\title{
Effect of technological properties of pea seeds and processing modes on efficiency of its dehulling
}

\author{
Yevgen Kharchenko', Andrii Sharan ${ }^{1}$, \\ Valentyn Chornyi ${ }^{1}$, Olena Yeremeeva ${ }^{2}$ \\ 1 - National University of Food Technologies, Kyiv, Ukraine, \\ 2 - Uman's National University of Gardening, Uman, Ukraine
}

\section{Keywords:}

Pea

Dehulling

Kernel

Husk

Dust middlings

Fine grits

\section{Article history:}

Received

23.04.2018

Received in revised form 29.06.2018

Accepted

27.12.2018

\section{Corresponding author:}

Yevgen Kharchenko E-mail:

a_537@nuft.edu.ua

DOI:

$10.24263 / 2304-$ 974X-2018-7-4-5

\section{Abstract}

Introduction. The process of dehulling grain peas is not enough researched, and there are difficulties of modeling the technological process as a whole. Presented research results of the process of pea seeds dehulling allow to understand the behavior of pea seeds during dehulling in machines with abrasive working members.

Materials and methods. Pea seeds of varying large-scale and moisture are scaly in the laboratory dehuller. The products of dehulling were cleaned in the aspiration channel from husk and dust middlings after this process the products were weighed and determined the dehulling index. By changing the moisture content (from 11,6 to 16,6\%) and the size of the pea seeds (from 213 to 257 $\mathrm{g}$ ), the speed of rotation of the working body of the dehuller (from 25 to $41,6 \mathrm{~s}^{-1}$ ), the duration of processing (from 5 to $25 \mathrm{~s}$ ) and the coefficient of filling the working chamber (from 0,09 to 0,48 ) of the machine was presented dependence of the parameters on dehulling efficiency.

Results and discussion. It is determined that the increase of processing time, the pea seeds, the speed of the working organs and filling coefficient of the working chamber of the dehuller increase the efficiency of dehulling peas by linear dependence. Increase in the size of pea seeds contributes to increase of efficiency of dehulling mainly due to increase of the yield of small. The increase in the scale of seeds leads to a decrease in the dehulling index.

Along with the increasing efficiency of dehulling, increases and yield of trinkets at the expense of the kernel. When the moisture of pea seeds increases, the yield of a fine grits increases comparing to the dehulling of dry pea. Yield of the kernel is directly proportional to the reduction of the yield of undehulling seeds. The yield of a fine grits also has linear dependencies when you change the following parameters.

In the process of dehulling reduces the ash content of the kernel, but also decreases the ash content and husk and dust middlings, which is the result of transition of low-ash content particles of kernel into the dust middlings.

Conclusions. For effective dehulling of pea seeds, it is necessary to carry out dehulling for $10-15 \mathrm{~s}$, filling coefficient of the machine must be not less 0,48 . Pea seeds with an absolute mass of $257 \mathrm{~g}$, dehull better than pea seeds with an absolute mass of 213 g. 


\section{Introduction}

Technological process of dehulling of pea seeds is carried out in abrasive grinding machines $[5,27,35]$. The process of dehulling has been researched, despite its extensive application in grain processing technologies [24,32]. This creates an obstacle to simulate the whole technological process.

The process of dehulling in abrasive machines is a scientific problem that requires detailed research and development of the function of dehullling, which will allow to develop quantitative balances of technological processes of processing pea seeds in cereals [16].

For cereals in which the shell is firmly increased with the kernel, to assess the efficiency of the dehulling process used dehulling index [11-13,21,22]. On the efficiency of the process of dehulling pea seeds affect its moisture and duration of processing. Prabhakar S., Phirke P.S., Bhole N.G. [21, 22] studied the dehulling index for two different types of pigeon peas depending on different ways of handling peas. Mathematical model of dehulling process was developed and process optimization was carried out.

With the increase in moisture the efficiency of the process of dehulling of legumes decreases [15, 23, 27, 33]. Goyal R.K., Vishwakarma R.K., Wanjari O.D. [13] investigated the effects of moisture on the efficiency of the dehulling process pigeon peas. They have established that with increased moisture above $10 \%$ the efficiency of the process is reduced. Opoku A., Tabil L., Sundaram J., Crerar W.J., Park S.J. [19] investigated different ways of handling pigeon peas to increase the yield of the kernel. It has been found that heat treatment contributes to an increase in the kernel of the pea. Tiwari B.K., Jaganmohan R., Venkatachalapathy N., Tito Anand M., Surabi A., Alagusundaram K. [31] optimized the influence of the process of hydrothermic treatment of pea seeds and its drying on the efficiency of seed dehulling pigeon peas. From their studies you can trace the increase in efficiency of dehulling with the increase of duration of hydro-thermal processing.

Goyal R.K., Vishwakarma R.K., The Wanjari O.D. [11, 12] has developed a mathematical model and optimized the process of dehulling pigeon peas. The mathematical model takes into account the pea moisture and duration of dehulling. These models do not take into account the large pea seeds and the filling of the equipment. The shortcomings of these models is that they can be used only for the dehullers on which the research is carried out and do not reflect all the features of the process of dehulling on other types of machines.

On the process of dehulling also affects the rotational speed of machine working organs [3, 10, 16, 17, 33]. Mangaraj S., Singh K.P. [17] developed a mathematical model and optimized the process of dehulling in the industrial machine, taking into account the speed of rotation of the working body, machine dimensions and machine performance.

One factor that affects the efficiency of dehulling is the scale of seeds [7, 10]. Most studies were conducted without regard to this factor.

Vereshchinskii A.P. [28] investigated the impact of the load on the effectiveness of wheat dehulling in the technologies of flour milling producing production. It has found that the amount of grain loaded into the dehuller affects the effectiveness of its dehulling by curved dependence.

Singh U., Santosa B.A.S., Rao P.V. [25, 26] studied efficiency of dehulling of different genotype pigeon peas. They have determined that different gene types of pea have different efficiency of dehulling.

Studies conducted by many scientists performed on the tangential abrasive dehulling device (TADD) $[6,8,10,18,19,21,24,26]$, which are structurally different from the industrial machines of continuous action. The main difference is the absence of the tangential 
abrasive dehulling device trellis, which is displayed by dehullling products: husk and dust middling.

Laboratory abrasive machines with lattice canvas $[4,8,11-13,15,27,31]$ are better suited for modeling the dehulling process, which occurs in industrial machines continuous action with trellis canvas [27] in the middle. The results of the studies that are obtained at the tangential abrasive dehulling device are less suitable for development of dehulling function for industrial analogues in connection with the other nature of the dehulling process. Construction of the tangential abrasive dehulling device (TADD) provides a dehulling by the force of friction of grain on the abrasive disc [24], the influence of other forces is insignificant. In the machines with trellis canvas there is dehulling due to friction on the abrasive disk, the friction of grain on the lattice canvas and friction between the seeds [16]. The tangential abrasive dehulling device does not allow to investigate the effect of filling on the efficiency of dehulling due to a limited amount of seeds, which can be covered in a machine [24].

Most of results of the research is devoted to the study of the process of dehulling pigeon peas. Information about the process of dehulling field peas is not enough. The disadvantage of many of these studies is that it is not considered a large scale of seeds of field pea, which is a factor that affects the efficiency of dehulling of pea seeds. Information on the influence of the above parameters on the efficiency of the dehulling of field pea insufficient purpose of this work was to study the influence of duration of dehulling, speed of rotation of working organs of dehuller and load on the efficiency of process dehulling field peas of different moisture and large size.

\section{Materials and methods}

\section{Materials}

The technological process of dehulling of the seeds of the field of different moisture and large size, when changing the parameters of work of dehuller and processing duration is investigated.

\section{Methods}

\section{Grain preparation for research}

Before the beginning of the research, pea seeds were cleaned from light impurities by means of transmission through a laboratory aspiration channel. The cleared pea seeds were sifted on a lattice with a diameter of holes of $5,0 \mathrm{~mm}$, which was allocated by a small faction of seeds, and the east is a large faction of seeds. The selected large faction of the seeds were subjected to repeated sifting on the same lattice canvas with a diameter of holes of 5,0 $\mathrm{mm}$ with a view of a more complete selection of small seeds. Partially dehulled, broken, eaten seeds selected from the main mass and directed to the waste. The research was conducted only with fully whole seeds, which had the whole seed shells.

The separation of peas on large and small fractions allowed to establish the influence of large pea seeds on the effectiveness of its dehulling under all other conditions.

\section{Method of determining the moisture content of pea seeds}

We have to choose from the main mass of the selected seeds of big and small fractions which were crushed in the laboratory mill. After that the crushed product of $5 \mathrm{~g}$ was dried in the dryer at a temperature of $130^{\circ} \mathrm{C}$, within 60 minutes. Then cooled in ecliptic and weighed in technical scales with the subsequent recalculation of moisture [2]. 


\section{Method of determination of bulk density and mass of 1000 seeds}

The volume weight of seeds of peas is determined when we load 1-liter seeds of peas in a pelvic container 14,20$]$.

Among the large and small fractions of pea seeds picked up 1000 whole seeds, after which the selected seeds were weighed [4]. Weighted samples were recalculated on the absolbno mass of pea seeds by the formula:

$$
A=\frac{100-W}{100} \times m_{1000}
$$

where $W$ - moisture pea seeds, $\%$; $m_{1000}$ - mass 1000 seeds, g.

\section{Method of humidisting of pea seeds}

The amount of water added to the pea seeds in order to increase its moisture was calculated by the formula:

$$
G_{w}=G_{g}\left(\frac{100-W_{0}}{100-W_{p}}-1\right),
$$

where $G_{w}, G_{g}$ - according to mass of water and mass of seeds, $\mathrm{kg} ; W_{0}, W_{p}$ - in accordance with the moisture of seeds initial and specified, $\%$.

After water was added to the grain, it was thoroughly stirred and left to be cut for three days in a closed container.

\section{Technique of dehulling pea seeds}

Dehulling of large and small fractions of pea seeds carried out in laboratory dehuller (model ULZ-1), by changing the speed of the working body of the machine with $25 \mathrm{~s}^{-1}(1500$ $\mathrm{rpm})$ to $41,6 \mathrm{~s}^{-1}(2500 \mathrm{rpm})$, and the duration of dehulling changed from 5 to $25 \mathrm{~s}$ with a step duration handling $5 \mathrm{~s}$ by using an electronic timer that is equipped with a dehuller.

The dehuller ULZ-1, is the analogue of the machine Satake Grain Testing Mill TM05 $[4,8,34]$. With the difference that in the machine ULZ-1 used trellis canvas with round holes with a diameter of $2,0 \mathrm{~mm}[16,28]$. Abrasive discs of 14A40CM mark.

The efficiency of the process of dehulling was determined by the dehulling index, which is calculated by the formula $[15,29,30,33,34]$ :

$$
I_{p}=\frac{m_{1}-m_{2}}{m_{1}} \cdot 100
$$

where, $m_{l}$ - mass of seeds to dehulling, $g$; $m_{2}$ - mass of kernel, small and half pea seeds after dehulling, g.

During the research on the installation of the effect of processing duration on the efficiency of dehulling process, mass of gravity was $100 \mathrm{~g}$. During research on the measurement of filling influence on efficiency of dehulling, mass of seeds of pea seed took 40, 80, 120, 160, $200 \mathrm{~g}$.

Products of dehulling passed through the aspiration channel on the scheme, which is shown on Figure 1. Air mode of aspiration channel was installed visually with the help of frequency converter of turnovers, so that only a husk and a dust middlings were taken to the bunker. Cleaned of husk and dust middlings shredding products were weighed and calculated the dehulling index in the percentage of formula 3. After weighing, purified products of dehulling were sorted on trellis canvas with diameter of holes $5,0 \mathrm{~mm}$ for the purpose of selection of trinkets. 


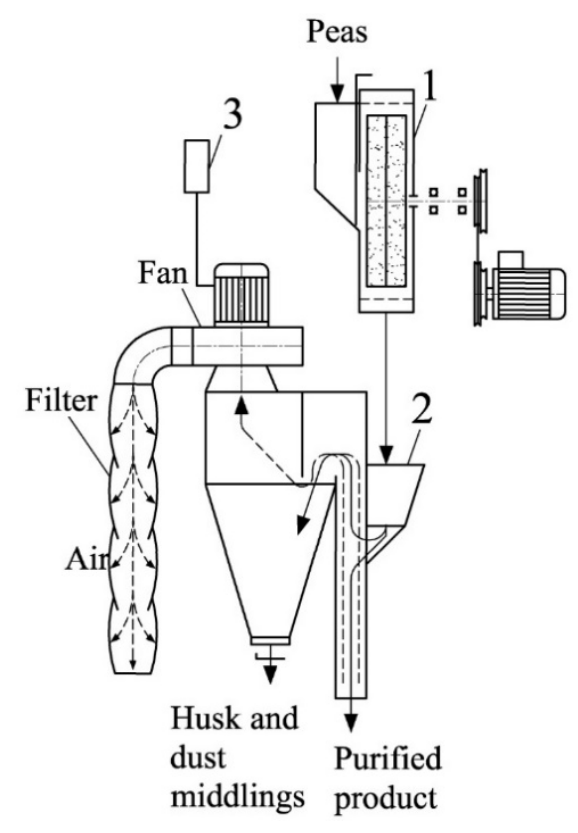

Figure 1. Scheme of research:

1 - dehuller; 2 - aspiration channel;

3 - frequency converter of revolutions

The selected trifle was also weighed and calculated its yield as a percentage, in relation to the general mass of pea seeds, which were directed on dehulling.

Method of research on the installation of influence of filling on efficiency of dehulling

Seeds of large and small fractions in the amount of 40, 80,120,160, 200 g separately scaly in the dehuller for $15 \mathrm{~s}$. The rotation speed of the working body of the machine was $25 \mathrm{~s}^{-1}$ (1500 rpm).

Products of dehulling passed through the aspiration channel (Figure 1) in order to separate the light impurities, after which they weighed and counted the dehulling index on the formula 3.

After weighing the products of dehulling were sifted on a lattice with a diameter of holes of $5,0 \mathrm{~mm}$ in order to isolate the crushed particles, which also weighed and calculated their yield as a percentage to the masses of undehulling seeds.

The obtained research data was used to determine the coefficient of filling the working chamber of the dehuller.

The coefficient of filling of working chamber of the dehuller was calculated by the formula:

$$
K=\frac{V_{g}}{V_{m}}
$$

where $K$ - is the coefficient of filling of working chamber of the dehuller; $V_{g}$ - volume of seeds loaded in the dehuller, $\mathrm{m}^{3} ; V_{m}$ - volume of working chamber of dehuller, $\mathrm{m}^{3}$.

Amount of grain was calculated by the formula:

$$
V_{g}=\frac{m}{\gamma}
$$

where $m$ - weight of seed, which is loaded into a dehuller, $\mathrm{kg} ; \gamma$ - bulk density peas seeds, $\mathrm{kg} / \mathrm{m}^{3}$.

Bulk density of large fraction amounted to $779 \mathrm{~g} / \mathrm{l}$, and weight of small fraction is 782 $\mathrm{g} / \mathrm{l}$.

The volume of the working chamber of the dehuller was calculated by the formula:

$$
V_{m}=\left(\frac{\pi D^{2}}{4}-\frac{\pi d^{2}}{4}\right) \cdot H
$$

where $D$ - respectively, the diameter of the lattice fabric of the dehuller and abrasive wheel, $\mathrm{m} ; H$ - height of the lattice of the dehuller, $\mathrm{m}$.

The diameter of the gray cylinder was $0,165 \mathrm{~m}$, diameter of abrasive discs $-0,15 \mathrm{~m}$. Height of sieve cylinder $-0,058 \mathrm{~m}$. 


\section{Methodology of the influence of moisture on the efficiency of dehulling}

In six containers of 0,51 filled with $200 \mathrm{~g}$ of pea seeds, added a calculated amount of water, which was calculated according to formula 2 , taking into account the primary moisture of the pea. The estimated moisture step was 1,0\%. After the addition of water, the tank closed the lids and moved intensively for 10 minutes and left on the drainage for three days.

After the sting of peas, from each tank was taken $40 \mathrm{~g}$ peas to determine the actual moisture, and $160 \mathrm{~g}$ peas were dehulled for $20 \mathrm{~s}$ and all other same conditions. The speed of the working body of the machine constituted $25 \mathrm{~s}^{-1}(1500 \mathrm{rpm})$.

The products of dehulling passed through the aspiration channel (Figure 1) with the purpose of separating the husk and the dust middlings, after which the cleaned products were weighed and calculated as a percentage of the dehulling index.

After weighing the products of dehulling sifted on a lattice with a diameter of holes of $5,0 \mathrm{~mm}$ in order to isolate the crushed particles, which also weighed and calculated their yield as a percentage.

The results of the researches were presented as dependence of "moisture - dehulling index". The research was carried out in three repetitions with large and small factions of peas separately.

\section{Technique of determining the ash content product of dehulling}

A large faction of pea seeds with moisture of $11,6 \%$ and an absolute mass of $257 \mathrm{~g}$ was scaly at the duration of $5,10,15,20,25 \mathrm{~s}$, the speed of rotation of the working body of the dehuller was $25 \mathrm{~s}^{-1}(1500 \mathrm{rpm})$. After each test the cleaning machine was thoroughly cleaned of all products to avoid mixing of products of different ash content, which were obtained at different duration of processing.

The ash content was determined by the following methods. The weight of $2 \mathrm{~g}$ was burned in a muffle furnace at a temperature of $600 \ldots 900{ }^{\circ} \mathrm{C}$ for 4 hours. The ash content indicator was determined by the dry substance by the formula $[1,9]$ :

$$
z=\frac{m_{g} \cdot 100 \cdot 100}{m_{p}(100-W)}
$$

where $m_{z}$ - ash content weight, g; $m_{p}$ - weight of sample of product, g; $W$ - product moisture, $\%$.

Separately determined the ash content of the kernel and the ash content mixture of husk and dust middlings.

\section{Results and discussion}

\section{Effect of processing duration on the efficiency of dehulling}

The researches found that between the duration of treatment in the dehuller and the efficiency of dehulling of pea seeds there is linear dependence regardless of moisture and large pea. And also the speed of rotation of the working body of the dehuller. Dependence of the dehulling index of large and small fractions of peas from the duration of processing are shown in Figure 2 and 3. 


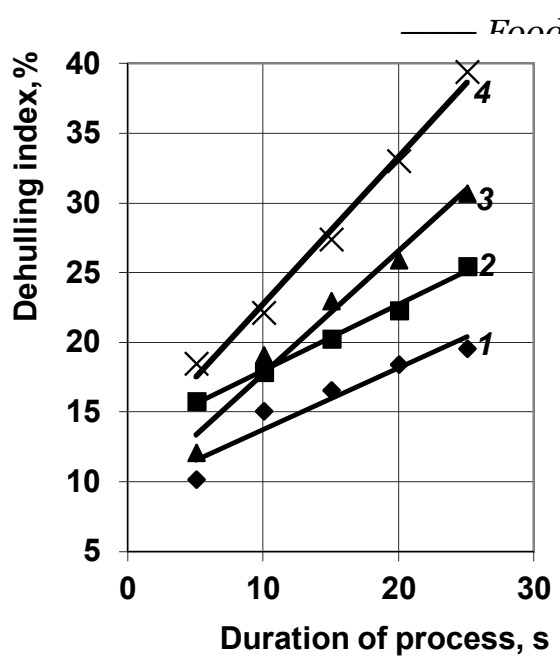

Figure 2. The dependence of the dehulling index large pea seeds faction from the duration of dehulling:

$1-\mathrm{W}=11,6 \%, \omega=25 \mathrm{~s}^{-1} ; 2-\mathrm{W}=11,6 \%, \omega$

$=41,6 \mathrm{~s}^{-1} ; 3-\mathrm{W}=16,6 \%, \omega=25 \mathrm{~s}^{-1}$;

$4-\mathrm{W}=16,6 \%, \omega=41,6 \mathrm{~s}^{-1}$

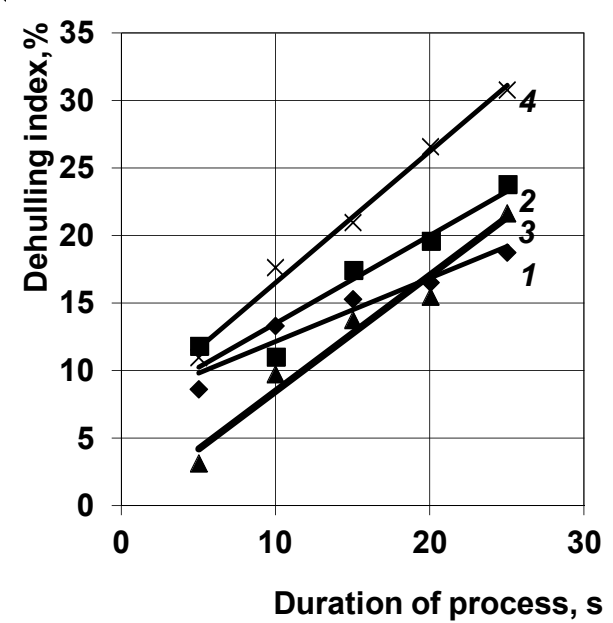

Figure 3. The dependence of the dehulling index large pea faction from the duration of dehulling:

$1-\mathrm{W}=11,6 \%, \omega=25 \mathrm{~s}^{-1} ; 2-\mathrm{W}=11,6 \%$, $\omega=41,6 \mathrm{~s}^{-1} ; 3-\mathrm{W}=16,6 \%, \omega=25 \mathrm{~s}^{-1} ; 4-\mathrm{W}$ $=16,6 \%, \omega=41,6 \mathrm{~s}^{-1}$

From Figure 2, you can see that regardless of all other factors increase the duration of processing in the dehuller from 5 to $25 \mathrm{~s}$ led to the increase in the dehulling index in the processing of large fraction of pea seeds, the absolute mass of which was $257 \mathrm{~g}$. The smallest efficiency of dehulling was observed at rotational speed of working body $25 \mathrm{~s}^{-1}$ and moisture of pea $11,6 \%$. The index was correspondingly increased from 10,2 to $19,6 \%$. Increase of rotation speed of working area of the dehuller from $25 \mathrm{~s}^{-1}$ to $41,6 \mathrm{~s}^{-1}$ increases the dehulling index on average by 5,0\%. Increasing the speed of the working body of the machine provides a more intense impact on the efficiency of the process, which leads to its increase.

Increased pea moisture from 11,6 to $16,6 \%$ led to increased efficiency of dehulling. At the speed of rotation of the working body of the dehuller $25 \mathrm{~s}^{-1}$, the dehulling index was increased from 12,2 to $30,8 \%$. Under these same conditions increase the speed of the rotation from 25 to $41,6 \mathrm{~s}^{-1}$ led to an additional increase in the dehulling index, which increased from 18,5 to $39,4 \%$.

The smallest efficiency of dehulling was observed at dehulling of dry seeds, regardless of its size. This can be explained by the fact that peas creates more resistance ripe than moist peas. With the increase in moisture of peas there is a violation of shells with the kernel, as well as the kernel becomes more plastic, which leads to a lighter abrasion in the action of abrasive bodies of dehuller and the increase of the yield of small [16].

From Figure 3 data, you can see that regardless of all other factors increase the duration of processing in the dehuller from 5 to $25 \mathrm{~s}$ led to the increase in the efficiency of dehulling while processing the small fraction of pea seeds, the absolute mass of which was $213 \mathrm{~g}$. The dehulling index was increased from 8,7 to $18,8 \%$. The increase in the rotation speed of the working body from $25 \mathrm{~s}^{-1}$ to $41,6 \mathrm{~s}^{-1}$ led to an additional increase in the dehulling index, which has changed from 11,9 to $23,8 \%$.

The increase in moisture of small fraction of peas from 11,6 to $16,6 \%$ led to increased efficiency of dehulling peas only at speed of rotation of working body of dehuller $41,6 \mathrm{~s}^{-1}$. At the speed of rotation of the working body of the dehuller $25 \mathrm{~s}^{-1}$ the reverse effect of 
influence was observed. Small peas with moisture of $16,6 \%$ scaly worse than peas with moisture of $11,6 \%$. The dehulling index was increased from 3,2 to $21,7 \%$. This may be the result of the fact that the small peas in damp condition carries more resistance to the comprestiance than dry.

The greatest efficiency of dehulling of small pea was observed at the moisture $16,6 \%$ and rotation speed of the working body $41,6 \mathrm{~s}^{-1}$. Under these conditions, the dehulling index was increased from 11,0 to $30,6 \%$.

Comparing Figures 2 and 3 can be seen that a large fraction of pea is more effective than small in all other same conditions. and the action of moisture on large seeds is more than small, resulting in greater importance of dehulling index. This can be explained by the fact that large pea seeds have less resistance to comprestiance than small.

In the process of dehulling, in addition to whole seeds of pea, formed pea fine gritz. The results of the study of a fine grits yield are shown in Figures 4 and 5.

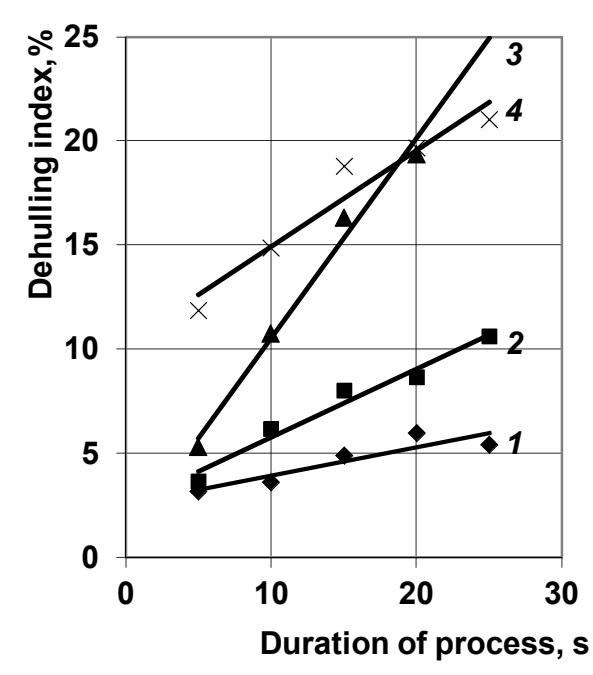

Figure 4. Dependency yield of fine grits at a different duration of dehulling of large pea fraction:

$$
\begin{gathered}
1-\mathrm{W}=11,6 \%, \omega=25 \mathrm{~s}^{-1} ; 2-\mathrm{W}=11,6 \% \\
\begin{array}{c}
\omega=41,6 \mathrm{~s}^{-1} ; 3-\mathrm{W}=16,6 \%, \omega=25 \mathrm{~s}^{-1} ; 4-\mathrm{W} \\
=16,6 \%, \omega=41,6 \mathrm{~s}^{-1}
\end{array}
\end{gathered}
$$

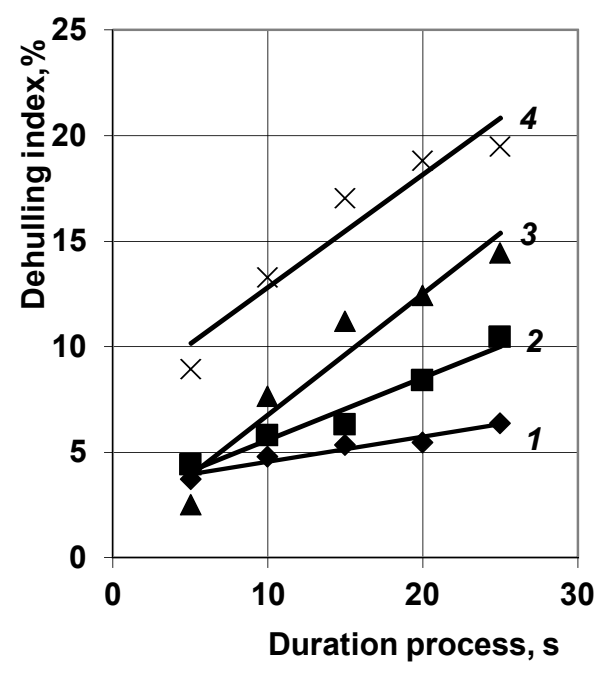

Figure 5. Dependency yield of fine grits at different duration of dehulling of small fraction of peas:

$1-\mathrm{W}=11,6 \%, \omega=25 \mathrm{~s}^{-1} ; 2-\mathrm{W}=11,6 \%$, $\omega=41,6 \mathrm{~s}^{-1} ; 3-\mathrm{W}=16,6 \%, \omega=25 \mathrm{~s}^{-1} ; 4-\mathrm{W}$ $=16,6 \%, \omega=41,6 \mathrm{~s}^{-1}$.

The smallest yield of fine grits at dehulling of a large fraction of peas was observed at moisture of pea $11,6 \%$ and speed of rotation of working body of dehuller $25 \mathrm{~s}^{-1}$. With the increase in the duration of processing from 5 to $25 \mathrm{~s}$ the yield of a small scale linearly increased from 3,2 to $5,4 \%$. Increase the rotation speed of the working body of the dehuller with $25 \mathrm{~s}^{-1}$ to $41,6 \mathrm{~s}^{-1}$, has led to an increase in the yield of a fine grits at dehulling of a large fraction of peas with moisture of $11,6 \%$.

Increased moisture of a large pea fraction from 11,6 to $16,6 \%$ substantially led to an increase in the yield of a fine grits. At the speed of rotation of the working body of the dehuller $25 \mathrm{~s}^{-1}$, the yield of a fine grits increased from 5,3 to $25,0 \%$ duration of dehulling from 5 to $25 \mathrm{~s}$. Increase the rotation speed of $25 \mathrm{~s}^{-1}$ to $41,6 \mathrm{~s}^{-1}$ led to an increase in the yield of a fine grits from 11,9 to $21,0 \%$. 
At the dehulling of small fraction of peas there is a similar effect of pea moisture and rotational speed of working body of the dehuller. The smallest yield of fine grits was observed at moisture of pea $11,6 \%$ and speed of the working body of the dehuller $25 \mathrm{~s}^{-1}$, with increasing the duration of the dehulling of small pea from $5 \mathrm{~s}$ to $25 \mathrm{~s}$, the yield of fine grits increased in accordance with 3,8 to $6,4 \%$. The increase of rotational speed of working body of the dehuller with $25 \mathrm{~s}^{-1}$ to $41,6 \mathrm{~s}^{-1}$, led to an increase in the yield of a fine grits, which increased depending on the duration of dehulling from 4,4 to $10,5 \%$.

With the increase in moisture small fraction of pea seeds from 11,6 to $16,6 \%$ yield of fine grits considerably increased by linear dependence. At rotational speed of working body of dehuller $25 \mathrm{~s}^{-1}$, the yield of a fine grits increased from 2,5 to $14,5 \%$, depending on the duration of dehulling, which ranged from 5 to $25 \mathrm{~s}$. With increasing speed of working body of dehull machine with $25 \mathrm{~s}^{-1}$ to $41,6 \mathrm{~s}^{-1}$ and the increase of moisture of small pea from 11,6 to $16,6 \%$, the yield of fine grits additionally increased from 9,0 to $19,5 \%$, with duration of dehulling from 5 to $25 \mathrm{~s}$.

Comparing the Figures 4 and 5, you can see that the yield of a fine grits is bigger in large pea faction. In the dehulling of dry pea seeds with moisture of $11,6 \%$, the yield of fine grits varies within 1,0\% regardless of the fraction of the faction, and with increasing moisture up to $16,6 \%$ of the yield of fine grits is increased for both large fraction and small. Larger yield of a fine grits traced at dehulling of large fraction.

The following data can be output: increasing the duration of dehulling, the rotation speed of the working body and the pea moisture leads to an increase in the yield of small. The smallest yield of fine grits was observed at dehulling of dry seeds as large and small, and with increase of moisture yield of fine grits increases, which is the result of change of its structural-mechanical properties.

Increase of the yield of a fine grits at increasing the speed of rotation of a working body of the dehuller can be explained by the fact that the more intensive action on pea seeds due to the frictional forces $[3,10,16,17,33]$. The effect of moisture to increase the yield of fine grits can be explained by the fact that moisture reduces the strength of connections in the middle of the kernel peas, due to which forms a larger yield of fine grits during dehulling [5,

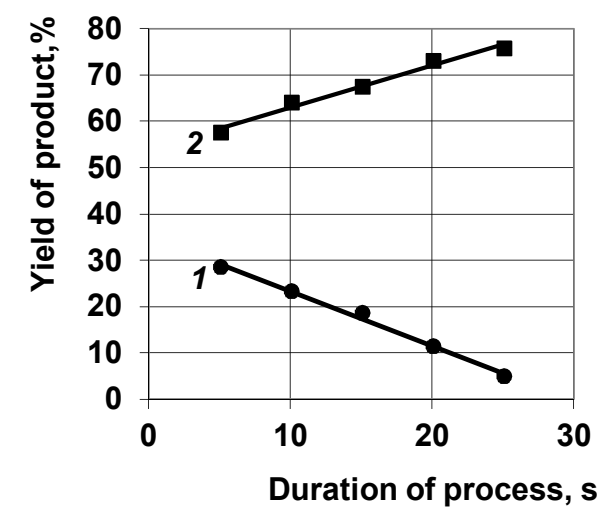

Figure 6. Yield of the kernel and undehulled seeds at fine pea dehulling:

1 - yield of undehulling seeds; 2 - yield of kernel 35].

During the processing of peas in groats, a fine grits is a byproduct. Increasing the yield of a fine grits leads to a decrease in the yield of the whole kernel, so it is necessary to try to reduce its yield, it can be achieved by processing dry pea.

Analyzing the data of the kernel yield and undehulled seeds, it is found that the yield of undehulled seeds varies linearly inverse of the yield of the kernel, as shown in Figure 6. With the increase in the yield of the whole kernel, the yield of undehulled seeds on the same amount decreases. The moisture of the pea was $13,6 \%$ and the speed of rotation of the working body of the dehuller totalled 41,6 $\mathrm{s}^{-1}$. 


\section{Effect of filling on efficiency of dehulling}

In order to establish dependence of influence of the load on the efficiency of dehulling the pea was perfomed study of the dehulling of large and small fractions of pea seeds at the constant duration of dehulling $15 \mathrm{~s}$, the constant speed of rotation of the working body of the dehuller, which amounted to $41,6 \mathrm{~s}^{-1}$ and the various pea moisture.

It is found that the dehulling of both large and small fraction of seeds of peas by moisture of $12,9 \%$, with increase in the mass of grain loaded into the dehuller, the dehulling index increases by linear dependence. This indicates that with all the immutable parameters of the process, the efficiency of dehulling will increase by increasing the mass of pea seeds in the dehuller. The results of research are shown in Figure 7.

When dehulling a large fraction of pea seeds with 17,4\% moisture (line 3 in Figure 7) was called the rotor of a dehuller, which was not observed when dehulling a small fraction with moisture of $16,8 \%$. This can be explained by the fact that the increase in the moisture of pea seeds leads to increased friction coefficient between seeds, at the expense of which increases resistance to the working body of the dehuller.

Having expressed a mass of grain due to the coefficient of filling of working chamber of dehuller we obtain dependence of the efficiency of dehulling from filling coefficient of working chamber of the dehuller at constant time of dehulling, which totalled $15 \mathrm{~s}$.

When dehulling large fraction of pea seeds with $12,9 \%$ moisture, the dehulling index was increased from 9,7 to $16,0 \%$. The coefficient of filling of working chamber of the dehuller was increased from 0,09 to 0,48 , as shown in Figure 8 . In the dehulling of the small fraction of peas with moisture $12,9 \%$, the dehulling index increased from 6,3 to $16,1 \%$ in the same conditions. This data shows that small pea fraction is less erased in the process of dehulling than large and requires greater duration of dehulling than a large fraction to achieve similar result.

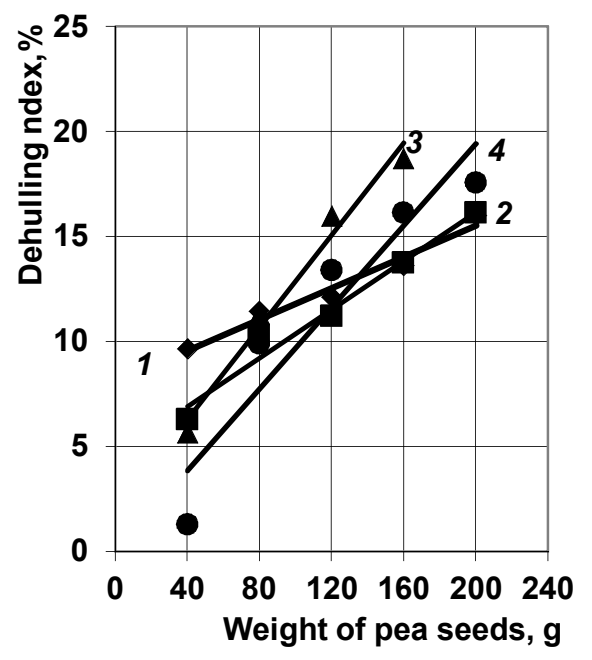

Figure 7. Dependence of the dehulling index from the amount of grain loaded in the

$$
\begin{gathered}
\text { dehuller: } \\
\begin{array}{c}
1-\mathrm{W}=12,9 \%, \mathrm{~A}=226 \mathrm{~g} ; 2-\mathrm{W}=12,9 \%, \mathrm{~A} \\
=196 \mathrm{~g} ; 3-\mathrm{W}=17,4 \%, \mathrm{~A}=226 \mathrm{~g} ; \\
4-\mathrm{W}=16,8 \%, \mathrm{~A}=196 \mathrm{~g}
\end{array}
\end{gathered}
$$

Figure 8. The dependence of the efficiency of dehulling on the fill factor of the working chamber:

$$
\begin{gathered}
1-\mathrm{W}=12,9 \%, \mathrm{~A}=226 \mathrm{~g} ; 2-\mathrm{W}=12,9 \% \\
\mathrm{~A}=196 \mathrm{~g} ; 3-\mathrm{W}=17,4 \%, \mathrm{~A}=226 \mathrm{~g} \\
4-\mathrm{W}=16,8 \%, \mathrm{~A}=196 \mathrm{~g}
\end{gathered}
$$


With increased moisture of a large pea seed fraction from 12,9 to $17,4 \%$, the dehulling index was increased from 5,6 to $18,7 \%$ depending on the coefficient of filling the working chamber of the dehuller from 0,09 to 0,48 . When the fine fraction of pea seeds with moisture $16,8 \%$, the dehulling index increased from 1,3 to $17,6 \%$ at the same coefficients of filling the working chamber of the dehuller.

Attention is paid to the fact that at the small filling of working chamber of the dehuller $(\mathrm{K}=0,1)$ with the dehulling of moist seed as large and small fractions of pea seeds The dehulling index is smaller and totalled 5,6\% and 1,3\% than in the processing of dry fractions pea seeds. For dry large and small fractions of pea seeds dehulling index was $9,7 \%$ and $6,3 \%$. This indicates that when the small filling of the working chamber dehuller, moisture seed increases the resistance of friction forces operating in the working area of the machine.

The research is determined that the yield of a trifle also has increased with the increase in the coefficient of filling of working chamber of dehuller by linear dependence, as shown in Figure 9.

The yield of small pea fraction with the moisture of $12,9 \%$ increased from 0,9 to $11,2 \%$, with the appropriate increase in coefficient of filling of working chamber from 0,09 to 0,48 . With the increase in the moisture of pea seeds of large fraction from 11,6 to $17,4 \%$ and increase of filling coefficient of working chamber of dehuller from 0,09 to 0,48 , the yield of small-scale increase from 1,9 to $15,9 \%$. The increase in the pea seeds of large fraction of the faction led to an increase in the yield of small.

When the meadow small fraction of pea seeds were observed the similar dependence. With the increase in the filling coefficient of working chamber of dehuller yield of smallscale machines increased from 0,9 to $12,2 \%$. With the increase in moisture of small fraction of pea from 12,9 to $17,4 \%$ and the corresponding change in filling coefficient of the working chamber of the dehuller from 0,09 to 0,48 , the yield of a small scale is increased linearly from 1,8 to $18,2 \%$.

The given research results show that the moisture and weight of the loaded pea seeds in the dehuller increase of the yield of a fine grits during the process of dehulling under all other conditions. This data also confirms the results of the study shown in Figure 2 and 3.

The duration of dehulling also influences the efficiency of the process. In order to establish a general effect on the efficiency of dehulling pea seeds processing duration and the coefficient of filling of working chamber of the dehuller was carried out by dehulling of large fraction of pea seeds with $12,6 \%$ moisture. The results of researches, which are shown in Figure 10 indicate a gradual increase of efficiency of dehulling under all other conditions.

Apparently from the drawing of 10 data with increase in coefficient of filling of the worker of chamber from 0.09 to 0.48 and with increase in duration of dehulling with 10 to 25 with dehulling the index while the nature of process remains invariable linearly increases.

The yield of fine grits is also subject to linear dependence, as shown in Figure 11. The largest yield of fine grits was observed at the duration of dehulling $25 \mathrm{~s}$ and the coefficient of filling of working chamber of the dehuller 0,48 , and the smallest yield of fine grits was observed the duration of dehulling $10 \mathrm{~s}$ and the coefficient of filling of working chamber of the dehuller 0,09 .

The given evidence indicates that the duration of finding pea seeds increases the dehulling index, but the nature of the process remains without changes. 


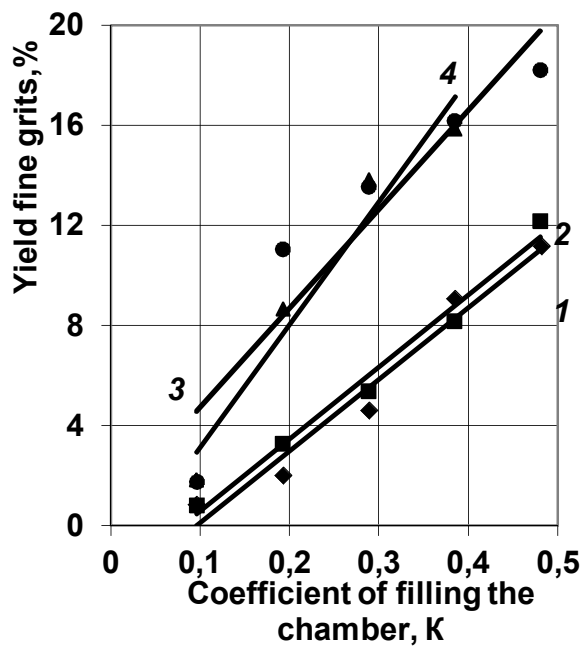

Figure 9. Dependence of a small yield depending on the coefficient of filling of working chamber of the dehuller:

$1-\mathrm{W}=12,9 \%, \mathrm{~A}=226 \mathrm{~g} ; 2-\mathrm{W}=12,9 \%$, $\mathrm{A}=196 \mathrm{~g} ; 3-\mathrm{W}=17,4 \%, \mathrm{~A}=226 \mathrm{~g}$; $4-\mathrm{W}=16,8 \%, \mathrm{~A}=196 \mathrm{~g}$

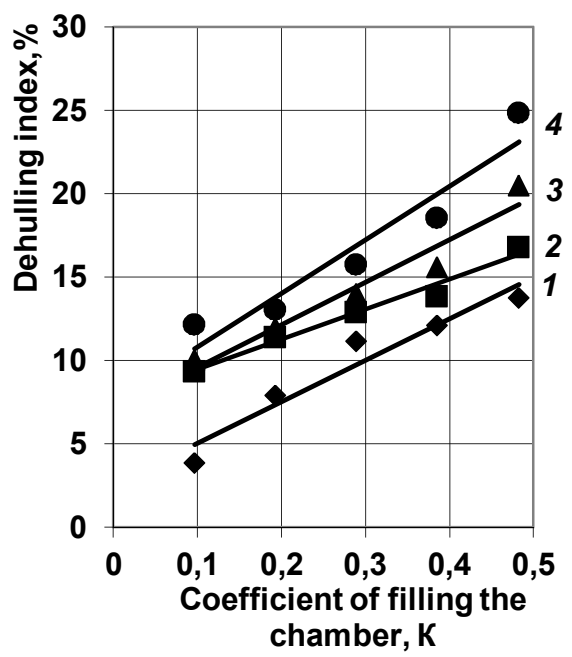

Figure 10. Influence of duration of dehulling and filling coefficient of working chamber for efficiency of dehulling:

$1-10 \mathrm{~s} ; 2-15 \mathrm{~s} ; 3-20 \mathrm{~s} ; 4-25 \mathrm{~s}$

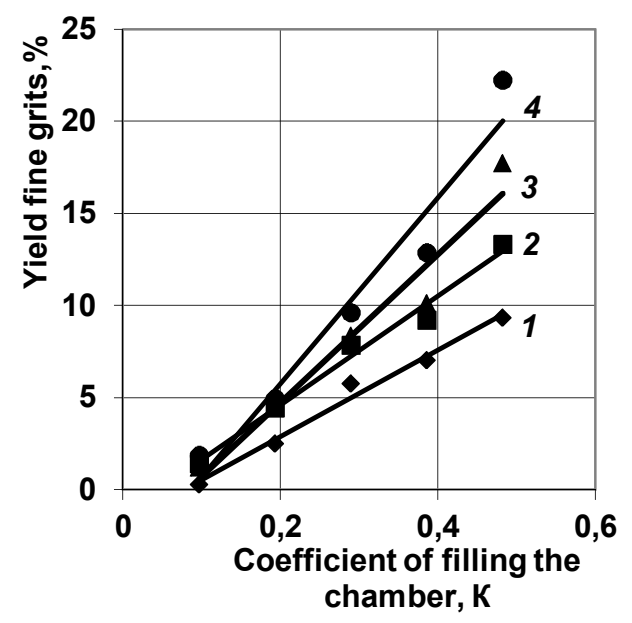

Figure 11. Yield fine grits at different duration of dehulling and coefficient of filling of working chamber of the dehuller:

$1-10 \mathrm{~s} ; 2-15 \mathrm{~s} ; 3-20 \mathrm{~s} ; 4-25 \mathrm{~s}$ 


\section{Investigation of moisture influence on the efficiency of dehulling peas}

The data of Figures 2 and 3 indicates that the moisture affects the efficiency of the dehulling of peas, however the character of this dependence remains unknown. Conducted researches have shown that with the increase in moisture of pea seeds the efficiency also increases with all other conditions of the process of dehulling, as shown in Figure 12. During the investigation of the absolute mass of seeds of large fraction amounted to $226 \mathrm{~g}$, the absolute mass of seeds of small fraction constituted $196 \mathrm{~g}$.

Figure 12 shows that the large fraction of the pea change of moisture from 10,8 to $16,5 \%$ led to the growth of the dehulling index from 15,6 to $27,4 \%$. When the small fraction was formed, the moisture was changed from 12,1 to $16,9 \%$, the dehulling index was smaller and increased from 15,1 to $22,6 \%$. The results obtained are consistent with the research of other researchers $[13,15,19,23,27]$.

Smaller values of the dehulling index confirm the previous research that the small peas are worse than the same for all other conditions.

With increasing the efficiency of dehulling due to the increase in the moisture of peas also increases the yield of fine grits at line dependence, as shown in Figure 13. The smallest yield of fine grits is observed at low moisture of peas, and with increased moisture of the pea, yield of small lines increases.

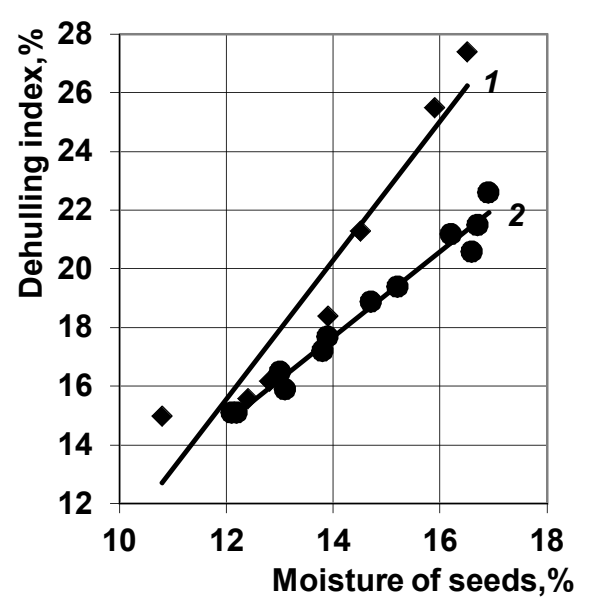

Figure 12. Effect of pea moisture on the efficiency of its dehulling:

1 - large fraction; 2 - fine fraction

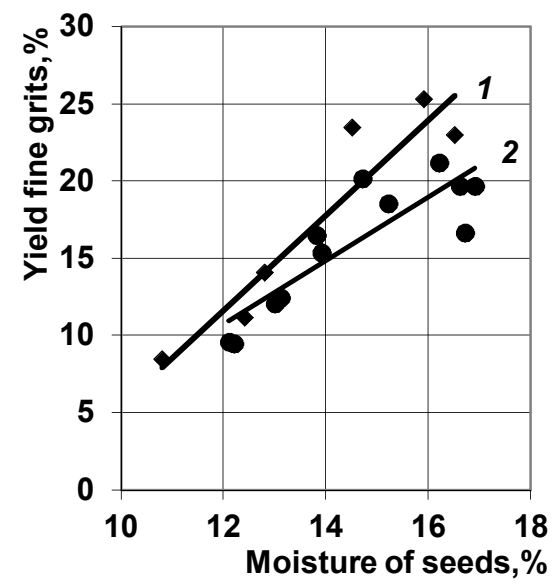

Figure 13. Yield of fine grits depending on the moisture of peas:

1 - large fraction; 2 - fine fraction

\section{Analysis of the ash content dehulling products}

By studies of ash content content of kernel, husk and dust middlings at the dehulling of a large fraction of peas found that the ash content is changing linearly depending on the duration of dehulling of pea seeds, as shown in Figure 14.

Data Figure 14 It is confirmed that the ash content content of dehulling linearly decreases with the increase of duration of dehulling. With the increase in the duration of the dehulling from $5 \mathrm{~s}$ to $25 \mathrm{~s}$, the kernel's ash content decreased from 2,86 to 2,42\%, under these conditions, the ash content content of husk and dust middlings decreased from 3,7 to $3,32 \%$. 


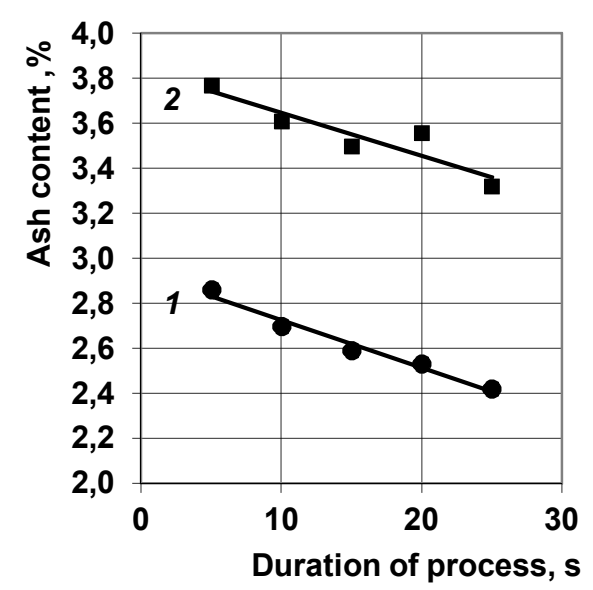

Figure 14. Change of ash content content of kernel, husk and dust middlings of large pea fraction:

1 - kernel; 2 - husk and dust middlings

From figure 14 data, you can see that the direct change in the ash content is parallel to one another. This indicates that with increasing the duration of dehulling of highash content products, which are separated from the kernel are transferred to products that form the flow of husk and dust middlings and have less ash content than husk and dust middlings. With a gradual decrease in the kernel of the kernel, the ash content particles are also diminished, which are sent to husk and dust middlings, which leads to a decrease in their ash content.

From these data it is possible to conclude that with the increase of duration of dehulling, the compression of a low-ash content kernel leads to decreasing of the flow of husk and dust middlings, which reduces the yield of the kernel and increases the yield of husk and dust middlings, whose ash content is also reduced.

The results of the researches give an opportunity to better understand the behavior of pea seeds in the dehulling process.

\section{Conclusions}

Scientific novelty of the results consists in the fact that it allows to understand the behavior of pea seeds in the process of dehulling during its processing at different parameters of the process.

1. Increasing the duration of dehulling from 5 to 25 and increases the efficiency of dehulling of pea seeds according to linear dependence, regardless of the size of the pea seeds.

2. Increase in the moisture of pea seeds from 11,6 to $16,8 \%$ also leads to increased efficiency of dehulling. Efficiency of dehulling with increase in moisture increases by increasing the yield of small.

3. Increase the rotation speed of the working body of the dehuller with $25 \mathrm{~s}^{-1}$ to $41,6 \mathrm{~s}^{-1}$ leads to increased efficiency of dehulling peas.

4. Big seeds of peas - a factor which reduces efficiency of dehulling..

5. At efficiency of dehulling also significantly influences the coefficient of filling of working chamber of the dehuller. Regardless of the large pea, increasing the coefficient of filling of the working chamber of the dehuller leads to increased efficiency of dehulling on linear dependence.

6. With the increase in duration of processing, the speed of the working body of the dehuller, the load factor of the working chamber of the dehuller, as well as moisture contributes to an increase in the yield of fine grits by decreasing the yield of the whole kernel. Under the same conditions, the yield of fine grits is smaller when the small fraction is at the expense of greater resistance to the joints.

7. The maintenance of ash-content of a kernel and peel and goods of average quality of dust - linearly reduction with the increasing process duration.. 


\section{References}

1. AACC. (2010), Approved methods of analysis, (11 ${ }^{\text {th }}$ edn.). AACC International, St. Paul: American Association of Cereal Chemists.

2. AOAC. (2016), Official Methods of Analysis of AOAC International, (20 ${ }^{\text {th }}$ edn.). AOAC International, Maryland, USA.

3. Baltabaev U.N., Tursunkhodzhaev P.M. (2011), Issledovanie vliianiia konstruktivnykh parametrov i tekhnologicheskikh protsessov shelushitelia na effektivnost shelusheniia iachmenia, Khranenie i pererabotka zerna, 11, pp. 65-67.

4. Black R.G., Singh U., Meares C. (1998), Effect of genotype and pretreatment of field peas (Pisum sativum) on their dehulling and cooking quality, Journal of the Science of Food and Agriculture, 77(2), pp. 251-258.

5. Dexter J.E., Sarkar A.K. (2003), Encyclopedia of food science and nutrition (Second Edition), Academic Press.

6. Ehiwe A.O.F., Reichert R.D. (1987), Variability in dehulling quality of cowpea, pigeon pea and mung bean cultivars determined with TADD, Cereal Chemistry, 64, pp. 81-93.

7. Erskine W., Williams P.C., Nakkoul H. (1991), Splitting and dehulling lentil (Lens culinaris): effects of seed size and different pretreatments, Journal of the Science of Food and Agriculture, 57, pp. 77-84.

8. George E., Rentsen B., Tabil L.G., Meda V. (2014), Optimization of wheat debranning using laboratiry equipment for ethanol production, International Journal of Agricultural and Biological Engineering, 7(6), pp. 54-66.

9. Ghavidel R.A., Prakash content J. (2007), The impact of germination and dehulling on nutrients, antinutrients, in vitro iron and calcium bioavailability and in vitro starch and protein digestibility of some legume seeds, $L W T, 40,1292-1299$.

10. Ghermezgoli K.M., Ghassemzadeh H.R., Moghaddam M. (2017), Optimization of Kabuli chickpea dehulling process, Journal of Biodiversity and Environmental Sciences, 10(2), pp. $115-125$.

11. Goyal R.K., Vishwakarma R.K., Wanjari O.D. (2008), Optimisation of the pigeon pea dehulling process, Biosystems Engineering, 99, pp. 56-61.

12. Goyal R.K., Vishwakarma R.K., Wanjari O.D. (2009), Optimization of process parameters and mathematical modelling for dehulling of pigeon pea, International Journal of Food Science \& Technology, 44, pp. 36-41.

13. Goyal R.K., Vishwakarma R.K., Wanjari O.D. (2010), Effect of moisture content on pitting and milling efficiency of pigeon pea grain, Food and Bioprocess Technology, 3(1), pp. 146 149.

14. ICC (2009), The ICC Handbook of cereals, flour, dough \& product testing. Methods and applications. (Stanley P. Cauvain, et al., eds), DEStech Publications, Inc.

15. Joyner J.J., Yadav B.K. (2015), Optimization of continuous hydrothermal treatment for improving the dehulling of black gram (Vigna mungo L), Journal of Food Science and Technology, 52(12), pp. 7817-7827.

16. Kharchenko Y.I., Sharan A.V. (2017), Shelushenie zerna iachmenia, Khranenie $i$ pererabotka zerna, 9, pp. 28-31.

17. Mangaraj S., Singh K.P. (2009), Optimization of machine parameters for milling of pigeon pea using RSM, Food and Bioprocess Technology, 4(5), pp. 762-769.

18. Oomah B.D., Ward S., Balasubramanian P. (2010), Dehulling and selected physical characteristics of Canadian dry bean (Phaseolus vulgaris L.) cultivars, Food Research International, 43, pp. 1410-1415.

19. Opoku A., Tabil L., Sundaram J., Crerar W.J., Park S.J. (2003), Conditioning and dehulling of pigeon peas and mung beans, CSAE, paper №03-347, pp. 2-17. 
20. Ponce-Garcia N., Ramirez-Wong B., Escalante-Aburto A., Torres-Chavez P.I., SernaSaldivar S.O. (2017), Wheat improvement, management and utilization, IntechOpen, pp. 275-291.

21. Phirke P.S., Prabhakar S., Bhole N.G. (2000), Pretreatment of pigeon pea grain for improvement of dehulling characteristics, International Journal of Food Science and Technology, 35, pp. 305-313.

22. Phirke P.S., Bhole N.G., Adhaoo S.H. (1996), Response surface modeling and optimization of dehulling of pigeon pea with different pre-treatments and conditions, Journal of Food Science Technology, 33, pp. 47-52.

23. .Ramakrishnaian N., Kurien P.P. (1983), Variabilities in the dehulling characteristics of pigeon pea (Cajanus cajan L.) cultivars, Journal of Food Science Technology, 20, pp. 287291.

24. Reichert R.D., Tyler R.T., York A.E., Schwab D.J., Tatarynovich J.E., Mwasaru M.A. (1986), Description of a production model of the tangential abrasive dehulling device and its application to breeders samples, Cereal Chem., 63(3), pp.201-207.

25. Singh U. (1995), Methods of dehulling of pulses: a critical appraisal, Journal of Food Science Technology, 32, pp. 81-93.

26. Singh U., Santosa B.A.S., Rao P.V. (1992), Effect of dehulling methods and physical characteristics of seeds on dhal yield of pigeon pea (Cajanus cajan L.) genotypes, Journal of Food Science Technology, 29, pp. 350-353.

27. Sokhansanj S., Patil R.T. (2003), Dehulling and splitting pulses. In: Handbook of Post Harvest Technology (Chakraverty A., et al., eds), Marcel Dekker, New York.

28. Vereshchinskii A.P. (2011), Svoistva i osobennosti vzaimodeistviia shlifovalnykh krugov s zernom v protsesse shelusheniia, Khranenie i pererabotka zerna, 11, pp. 62-65.

29. Vishwakarma R.K., Shivhare U.S., Gupta R.K., Yadav D.N., Jaiswal A., Prasad P. (2017), Status of pulse milling processes and technologies: A review, Critical Reviews in Food Science and Nutrition, 58(10), 1615 - 1628.

30. Sreerama Y.N., Sash contentikala V.B., Pratape V.M. (2009), Effect of enzyme predehulling treatments on dehulling and cooking properties of legumes, Journal of Food Engineering, 92, pp. 389-395.

31. Tiwari B.K., JaganMohan R., Venkatachalapathy N., Tito Anand M., Surabi A., Alagusundaram K. (2010), Optimisation of hydrothermal treatment for dehulling pigeon pea, Food Research International, 43, pp.496-500.

32. Yasmin A., Zeb A., Khalil A.W., Paracha G.M.D., Khattak A.B. (2008), Effect of processing on anti-nutritional factors of red kidney bean (Phaseolus vulgaris) seeds, Food and Bioprocess Technology, 1(4), pp. 415-419.

33. Wang N. (2005) Optimization of a laboratory dehulling process for lentils (Lens culinaries), Cereal Chemistry, 82(6), 671-676.

34. Wang N., Hatcher D.W., Gawalko E.J. (2008), Effect of variety and processing on nutrients and certain anti-nutrients in field peas (Pisum sativum), Food Chemistry, 222, pp. 132-138.

35. Wrigley C. (2004), Encyclopedia of Grain Science, Academic Press, North Ryde. 